clinical judgement. It is well known that in many hospitals the admission of patients who have been placed on Hospital Orders by the Courts is automatically vetoed by nursing staff. Where this is the case, it would seem more desirable that the psychiatrists concerned should state this in their reports, so that responsibility can be placed where it truly belongs.

If we as a profession are not prepared to do this, then it ill becomes us to criticise the acts of psychiatrists in totalitarian states, as we would seem ourselves to be on the first slippery steps of that particular slope.

St. Andrew's Hospital,

Northampton NNI 5DG

\section{REGIONAL SECURE UNITS}

Dear Sir,

The account of Lord Longford's speech on Mentally Abnormal Offenders (Bulletin, November 1978, p 189) might lead one to suppose that at Knowle Hospital the Shop Stewards were utterly opposed to the provision of any local care for the Mentally Abnormal Offender. This has been far from the truth. Once they had been acquainted with the clinical problem which the Mentally Abnormal Offender presents, they proved to be extremely helpful and positive in their approach to find a solution at a local level for the appropriate cases. They took the very interesting and stimulating view that a permanently physically secure unit was the wrong way of approaching the clinical and management problems presented by the patients discussed in the Glancy and Butler Reports. Their fear was that such a unit which was permanently and physically secure could easily deteriorate, especially under periods of staff reductions, into a punitive and untherapeutic establishment ( $c$ the experience of South Ockenden Hospital). They also feared that the presence of a permanently secure unit would lead to pressure being brought on the managers of the unit to admit more dangerous patients than the unit was really able to cope with. They held the view that a unit should be developed which should, as far as possible, be open (although the facility to lock it or make it secure would always be present if needed for temporary periods). The patients we would be expected to look after would inevitably have to return to the community sooner or later, and therefore the unit, as far as possible, should be community orientated, i.e. have sufficient nursing staff to provide a community nursing service and develop its own 'Group Home System'. It was also seen as very important that the unit should not be isolated and elitist, but fit in with the rest of the hospital in which it was placed.

These principles have, in fact, been incorporated in the Wessex Interim 'Secure' Unit. The efficacy of this unit has been described in a paper read at the Annual Meeting of the College on 6 July 1978. It was demonstrated that the Unit has made a substantial contribution to help alleviate the problem of providing hospital care for the mentally abnormal patients whom conventional hospitals are unable to admit. In the development of this Unit along these lines, the Shop Stewards have been nothing but helpful, and continue to be fully supportive.

Regional Consultant Forensic Psychiatrist,

M. FAULK Knowle Hospital, Fareham

Hampshire PO17 5NA

Dr Faulk's paper (abbreviated), will be published in the next issue of the Bulletin.

Eds.

\section{APPROVAL PROCEDURES}

\section{DeAr SiR,}

We have recently been visited for approval purposes by an inspection team from the College, and we understand that our status is to be reduced from 'Fully' to 'Provisionally'. Which, of course, has nothing to do with our writing.

It occurs to us that the time-consuming business of visiting is manna to work-starved obsessionals, and the rest of us should be grateful for the burden they so willingly and cheerfully assume. There may be one or two disadvantages, however, arising from the particular traits of the breed. We would draw attention to the following examples.

1. Perfectionism may lead to unrealistic standards being expected, far beyond what is intended-an obvious source of interjudge unreliability.

2. Rigidity of thinking may prevent appreciation of differing local customs and circumstances, leading to unfair assessment.

3. Personal insecurity may be compensated for by a certain abrasiveness of manner which impresses the visited as unnecessary aggressiveness.

4. Excessive rumination, heedless of the passage of time, may disrupt the clinical work of the visited hospital, and produce further irritation-especially

- if the visitors arrive late in the first place (excessive hand-washing?).

W. A. ElLiott

K. M. G. KEDDIE

Sunnyside Royal Hospital,

A. N. MUNRO

Montrose,

Angus, Scotland 